\title{
Investigation of the risk factors of pressure ulcers in intensive care unit patients: According to the Braden Scale*
}

\author{
Pakize Özyürek ${ }^{1, * *}$, Meryem Yavuz ${ }^{2}$,̈zlem Yıldız ${ }^{3}$ \\ 1 Department of Surgical Nursing, Health School, Afyon Kocatepe University, Afyonkarabisar \\ ${ }^{2}$ Department of Surgical Nursing, Faculty of Nursing, Ege University, Izmir \\ 3 Surgical Intensive Care Unit, Medical Faculty Hospital, Afyon Kocatepe University, Afyonkarabisar
}

\begin{abstract}
The study was planned as a descriptive study investigating the frequency of pressure ulcers in intensive care units and the correlation between pressure ulcers and Braden risk factor scores.

A total of 414 patients who were admitted to the stated intensive care units between October 1, 2008 and January 4, 2010 were evaluated. Among those, 323 patients met the inclusion criteria and were included in the study. The Braden Risk Assessment Scale was used for risk evaluation.

The incidence of pressure ulcers in the intensive care units was $17.0 \%(\mathrm{n}=55)$. According to the Braden Risk Assessment Scale, only $12.3 \%(\mathrm{n}=40)$ of the patients had no risk of pressure ulcer development. The incidence of pressure ulcer development in the internal medicine intensive care unit was significantly higher than that of surgical medicine intensive care unit $(\mathrm{p}=0.00)$. Anemic patients with a long duration of hospital stay, low level of albumin, and who were hospitalized in the internal medicine intensive care unit were determined to be statistically significantly at "very high risk" of pressure ulcer development $(p<0.05)$. A statistically significant correlation was observed between the risk levels of the patients and pressure ulcer development $(\mathrm{p}=0.04)$.
\end{abstract}

According to the results of this study, the duration of hospital stay, immobility, obesity, unconsciousness, friction, and rupture parameters are risk factors that lead to the development of pressure ulcers.

Key Words: Pressure ulcer, intensive care unit, Braden Risk Assessment Scale, risk factors

\section{Introduction}

Pressure ulcers (PUs) are recognized worldwide as one of the five most common causes of harm to patient, a largely preventable patient safety problem. PU are increasingly described as an indicator of quality of the care in intensive care units (ICUs) by health care organizations (1).

PUs are commonly defined as pressure or rupture related localized wounds in the skin over the bony process and/or the tissues beneath (2). Currently, PUs continue to be a serious health problems that increases the risk of infection, patient suffering, treatment costs and length of stay in ICU, furthermore, PUs also reduce the quality of life for the patient (3-5). Although the prevention and treatment of PUs necessitates a multidisciplinary team approach, everybody is like-minded in their opinion that nurses are foreground in preventing PUs $(6,7)$. Furthermore, PUs are an indicator of the quality of the nurse-specific provided by health care organizations (8-10).

In studies conducted before 2008-2009 reveal a reduction in the prevalence of PUs in hospitals (4\%-20\%), (4,11-14). However, the prevalence of PUs in intensive care units varies between $9 \%$ and $42 \%$ which is still frequent (15).

The number of studies on the prevalence and incidence of PUs in intensive care units is limited in our country. The incidence of PUs in the neurology intensive care unit was reported to be $18.3 \%$ in the study of Kurtulus and Pinar (16), $4.8 \%$ in the surgery intensive care unit in the study of Karadağ and Gümüşkaya (17), 11.6\% in the

${ }^{*}$ The some data of this study were based on the first author's PhD thesis (Department of Surgical Nursing, Institute of Health Sciences, Ege University, İzmir, Turkey)

${ }^{* *}$ Corresponding Author: Pakize Özyürek, Department of Surgical Nursing, Afyon Kocatepe University Health School, A Blok, Ali Cetinkaya Kampusu, Izmir Karayolu 5. Km, Afyonkarahisar 03200, Turkey 
study of Uzun and Tan (18), $14.3 \%$ in the study of Sayar et al. (19) and $10.4 \%$ in the study of Inan and Oztunc (20). Therefore, risk assessment is very important to identify of patients who are at high risk of developing PU in ICUs, in order to encourage effective PU management $(21,22)$.

PU risk assessment scales recently are used widespread in ICUs for preventing PUs in the patients (22). In various studies examined validity and reliability of the following scales such as Braden and Waterlow (21). PU risk assessment scales recently are used widespread in ICUs for preventing PUs in the patients (22). In various studies examined validity and reliability of the following scales such as Braden and Waterlow (21). Although the importance of using PUs risk assessment scales and incidence rates in ICU is highest, risk assessment scales are not widely used in Turkey $(8,23)$. In studies conducted in Turkey demonstrate that only $10-17 \%$ of nurses have used the Risk Assessment Scales of Braden and Norton $(8,23)$. The most frequently used scale in the States is the Braden scale $(15,23)$. The most frequently used scale in the United States is the Braden Scale $(15,24)$. In studies showed that the Braden scale has the highest validity in ICU' patients and detailed explanations of risk factors comprising the Braden Scale $(15,25,26)$. Therefore, this study was selected the Braden Scale to identify patients at level of risk for development of PU in ICUs.

This study was planned due to the limited number of the incidence of PUs studies in Turkey. The purpose of this study was to determine incidence, risk factor for PUs development in ICU patients according the Braden Scale.

\section{Materials and method}

\section{Sample}

The study was conducted as a descriptive and prospective study in the Medical and Surgical ICUs of a university hospital between 1 October 2008 and 4 January 2010. Each ICU had five bed unit in which eight nurses worked. Patients were included if they were 18 years or older and had an the Medical and Surgical ICUs stay of 24 hours or greater. 91 patients did not meet study criteria for multiple reasons and were excluded. After the first evaluation, patients who met the criteria were included in the study. PU risk was evaluated by the Braden Scale. Risk factors identified in this assessment led to an individualized plan of care to minimize the effects of friction and shear, sensory perception, general health status, and body temperature. The study was completed with a total of 323 patients. The study was planned as a descriptive and analytic study.

This study was approved by the institutional review Afyon Kocatepe University. Written approvals to perform the study were received from the Ethics Board of the Ege University School of Nursing and the University Hospital Medical and nursing directors of Research and Practice Hospital. For patients who were unconscious, written consent was obtained from relatives.

\section{Data Collection}

Data collection form: The data collection form, which was prepared by investigators to determine characteristics of patient, was used for documenting sociodemographic and medical conditions that could be PU risk factors, including age, gender, height and body mass index (BMI) of the patients, the ICU of admission, length of stay, levels of albumin and haemoglobin, drug treatment received, presence of any systemic disorders and level of consciousness. The patients' level of consciousness was evaluated using the Glasgow Coma Scale (GCS). The GCS gave a total consciousness score between 3 and 15, which was obtained from three parameters including (I) Eye response, (II) verbal response, (III) and motor response. A score of 3 indicates the "worst" and a score of 15 indicates the "best" consciousness level. Score of less than 8 on the GCS demonstrates "severely damaged". Scores between 9-12 demonstrates "moderately damaged" and scores between 13-15 defines "mildly damaged" consciousness (27). BMI is obtained by dividing the body mass by the square of the height. A BMI of less than 19 score symbolized "thin", $19-24.9$ is "normal", $25-30$ is "fat", and $>30$ is "obese".

Braden Scale: The Braden Scale for predicting PU risk, is a instrument that was developed in 1987 by Barbara Braden and Nancy Bergstrom. The purpose of the scale is to help health professionals, especially nurses, assess a patient's risk of developing a PU $(16,23,28)$. The Braden Scale is composed of six subscales that reflect sensory perception, skin moisture, activity, mobility, friction and shear, and nutritional status. Each subscale is rated on a scale of 1 to 4, excluding the 'friction and shear' category which is rated on a $1-3$ scale $(28,29)$. This combines for a possible total of 23 points, with a higher score meaning a lower risk of developing a PU and viceversa. A score of 23 means there is no risk for developing a PU while the lowest possible score of 6 points represents the severest risk for

East J Med Volume:21, Number:1, January-March/2016 
developing a PU. Patients with a total score of 12 or less are defined to be at high risk of PU development, those with a score between 13-14 are defined to be at moderate risk and those with a score between 15-16 are defined to be at low risk. In the elderly, at 75 years of age or older, a score between $15-18$ is accepted as low risk $(16,24,28,30)$. The validity and safety study for this scale was first conducted stageby Oguz in Turkey and was repeated by Pinar and Oguz in Turkey and the reliability and the validity of the scales were found to be quite high in both $(16,24)$. The Cronbach's alpha value was determined to be 0.98 in this study.

Pressure Ulcer Assessment Form: Patient's skin were assessed regularly to check for signs of PU development by nurses. In addition, for patients in whom a PU developed, the number of hours into the admission the PU occurred and the anatomical location and stage of the PU according to the 2009 National Pressure Ulcer Advisory Panel (NPUAP) staging system were recorded (31). The most widely used PU classification guideline recently classifies PUs in four stages system. According to that classification, in Stage I, intact skin with non-blanchable redness of a localized area usually over a bony prominence. In Stage II, partial thickness loss of dermis presenting as an intact or open/ruptured serum-filled or serosanginous filled blister. Full thickness tissue loss is observed in Stage III. Slough may be present but does not obscure the depth of tissue loss. In Stage IV, Full thickness tissue loss with exposed bone, tendon or muscle. Slough or eschar may be present (31).

\section{Data analysis}

Data was analysed the SPSS 14.0 package program. Descriptive statistic included frequency distributions for study variables and sociodemographic data. All comparisons were undertaken on an item by item basis and differences assessed by chi-square. The level of statistical significance was accepted as $\mathrm{p}<0.05$.

\section{Results}

In this study, the risk factors of patients were evaluated according to the Braden Scale. Of the 414 patients admitted to the Medical and Surgical ICUs during the study period, 323 met inclusion criteria and were in the final sample. The mean age of the 323 patients was $61.02 \pm 18.48$ years and $66.3 \%$ were over 60 years of age. Among the patients accepted in the ICUs, $44.6 \%$ were female and $55.4 \%$ were male. The mean length of stay in the ICU was $7.7 \pm 12.5$ days. $71.8 \%$ of patients stayed between 3 and 16 days in ICU. When the BMI values of the patients, $4.0 \%$ were cachectic, $37.1 \%$ were obese, $24.1 \%$ had a normal body weight, $21.0 \%$. The activities for $35 \%$ of the patients dependent, $6.8 \%$ partially dependent, $22.9 \%$ uncooperative, $19.2 \%$ were moderately cooperative, $21.5 \%$ were anemic, $75.9 \%$ had a low albumin level, $17 \%$ received sedation, and 17\% received cortisone therapy (Table 1).

In the evaluation of Braden scores of the patients, $40.8 \%$ were classified as at risk, $20.7 \%$ as at moderate risk, $16.4 \%$ as at high risk and $8.9 \%$ were as at very high risk. The rate of PUs development increased with an increase in the risk level of the patients according to the Braden Scale. This correlation was statistically significant (Table $1 ; \mathrm{p}=0.04$ )

Independent variables significantly associated with the dependent development of PU were assessed in this study. No statistically significant difference was found for PU development according to patients' age and gender. $(p>0.05)$. There was a statistically significant correlation found between length of stay and PU development $(\mathrm{p}<0.05)$. $29.7 \%$ were treated in the medical intensive care unit, and $70.3 \%$ were treated in the surgical ICU. The PU development rate in the Medical ICU was significantly higher than that in the Surgical ICU $(\mathrm{p}=0.00)$. A statistically significant difference was found in the $37.1 \%$ obese patients, (Table 1; $\mathrm{p}=0.03)$. Mobility and GCS were found to have a statistically significant difference for PU development $(p<0.05)$. In addition, there were no statistically significant differences found for PU development according to level of anemic, diabetic, sedated, albumin and using cortisone (Table 1; $\mathrm{p}>0.05$ ).

This study investigated the correlation between the PU development and the Braden Scale subscales. The sensory perception subscales, and friction and rupture subscales were the Braden Scale that were found to have a statistically significant relationship with PU development (Table 2; $\mathrm{p}<0.05$ ).

The incidence of PUs in patients at risk for PU according the Braden Scale in ICUs this study was observed in $17 \%$ of the patients. Stage I PUs developed in $13 \%$ patients, Stage II developed in $4.3 \%$, Stage III developed in $0.3 \%$, and no Stage IV PUs developed in any of the patients (Table 3). The PUs were observed mostly in the sacral $(49.5 \%)$, scapula $(20.0 \%)$, trochanter $(14.1 \%)$ and malleolus $(5.7 \%)$ regions (Table 3 ).

East J Med Volume:21, Number:1, January-March/2016 
Table 1. The relation between PUs and baseline clinical details of patients

\begin{tabular}{|c|c|c|c|c|}
\hline Clinical details of patient & n (\%) & $\begin{array}{l}\text { New Development } \\
\text { PUs (n) }\end{array}$ & $\begin{array}{l}\text { No Development } \\
\text { New PUs (n) } \\
\end{array}$ & $\mathrm{p}$ \\
\hline \multicolumn{5}{|l|}{ Years } \\
\hline 60 and $<$ years & $109(33.7)$ & 14 & 95 & \multirow[t]{2}{*}{$\mathrm{p}=0.10$} \\
\hline $60>$ years & $214(66.3)$ & 41 & 173 & \\
\hline \multicolumn{5}{|l|}{ Gender } \\
\hline Female & $144(44.6)$ & 29 & 115 & \multirow{2}{*}{$\mathrm{p}=0.10$} \\
\hline Male & $179(55.4)$ & 23 & 153 & \\
\hline \multicolumn{5}{|l|}{ Length of stay } \\
\hline $3-16$ days & $232(71.8)$ & 12 & 220 & \multirow{4}{*}{$\mathrm{p}=0.00$} \\
\hline $17-30$ days & $46(14.2)$ & 13 & 33 & \\
\hline $31-44$ days & $18(5.6)$ & 14 & 4 & \\
\hline $45 \geq$ days & $27(8.3)$ & 16 & 7 & \\
\hline \multicolumn{5}{|l|}{ Admission ICU } \\
\hline Surgical ICU & $227(70.3)$ & 29 & 67 & \multirow[b]{2}{*}{$\mathrm{p}=0.00$} \\
\hline Medical ICU & $96(29.7)$ & 26 & 201 & \\
\hline \multicolumn{5}{|l|}{ BMI } \\
\hline Unkonwn & $112(34.6)$ & 9 & 93 & \multirow{4}{*}{$\mathrm{p}=0.03$} \\
\hline$<18.4=$ underweight & $13(4.0)$ & 6 & 7 & \\
\hline 18.5-24.9=normal weight & $78(24.1)$ & 13 & 65 & \\
\hline $25>=$ obesity & $120(37.1)$ & 17 & 103 & \\
\hline \multicolumn{5}{|l|}{ Mobility } \\
\hline Immobile & $35(10.8)$ & 2 & 33 & \multirow{5}{*}{$\mathrm{p}=0.01$} \\
\hline Bed rest/ equipment assist & $22(6.8)$ & 2 & 20 & \\
\hline Crutches/walker & $72(22.2)$ & 7 & 35 & \\
\hline Mobile/active & $110(34.0)$ & 18 & 92 & \\
\hline Nurse assist & $114(35.2)$ & 26 & 88 & \\
\hline \multicolumn{5}{|l|}{ Braden Score } \\
\hline 19-23 score $=$ No risk & $40(12.3)$ & 0 & 40 & \multirow{5}{*}{$\mathrm{p}=0.04$} \\
\hline $18-15$ score $=$ risk & $132(40.8)$ & 22 & 110 & \\
\hline $14-13$ score $=$ moderate risk & $67(20.7)$ & 14 & 53 & \\
\hline $10-12$ score $=$ high risk & $53(16.4)$ & 12 & 41 & \\
\hline$\leq 9=$ very high risk & $29(8.9)$ & 7 & 22 & \\
\hline \multicolumn{5}{|l|}{ Glasgow Coma Score } \\
\hline $13-14$ score $=$ Minor & $187(57.9)$ & 24 & 163 & \multirow{3}{*}{$\mathrm{p}=\mathbf{0 . 0 2}$} \\
\hline 12-9 score $=$ Moderate & $62(19.2)$ & 13 & 49 & \\
\hline $8-3$ score $=$ Severe & $74(22.9)$ & 18 & 56 & \\
\hline \multicolumn{5}{|l|}{ Cortisone drug Use } \\
\hline Yes & $58(17.9)$ & 7 & 4 & \multirow{2}{*}{$\mathrm{p}=0.40$} \\
\hline No & $265(82.0)$ & 48 & 217 & \\
\hline \multicolumn{5}{|l|}{ Sedation drug use } \\
\hline Yes & $58(17.9)$ & 15 & 43 & \multirow[t]{2}{*}{$\mathrm{p}=0.10$} \\
\hline No & $265(82.0)$ & 40 & 225 & \\
\hline Diabetes Mellitus & & & & \\
\hline Unknown & $27(8.3)$ & 6 & 21 & \\
\hline Yes & $88(27.2)$ & 13 & 75 & $P=0.60$ \\
\hline No & $280(86.6)$ & 36 & 172 & \\
\hline Albumin (g/dl) & & & & \\
\hline$<3.5 \mathrm{gr} / \mathrm{dl}$ & $245(75.9)$ & 41 & 204 & \\
\hline $3.5 \mathrm{gr} / \mathrm{dl} \geq$ & $78(24.1)$ & 14 & 62 & $\mathrm{p}=0.30$ \\
\hline Haemoglobin level (g/dl) & & & & \\
\hline Unknown & $75(23.2)$ & 5 & 70 & \\
\hline$<10 \mathrm{~g} / \mathrm{dl}$ & $68(21.05)$ & 10 & 58 & $\mathrm{p}=0.30$ \\
\hline $10 \mathrm{~g} / \mathrm{dl} \geq$ & $230(71.3)$ & 40 & 190 & \\
\hline Total & $323(100)$ & 55 & 323 & \\
\hline
\end{tabular}


In this study, PU development was observed in $17 \% \quad(n=55)$ of the patients. I. stage PUs developed in $42(13 \%)$ patients, II. stage developed in $14(4.3 \%)$, III. stage developed in 1 $(\% 0.3)$, and no IV. stage PUs developed in any of the patients (Table 3). The PUs were observed mostly in the sacral (49.5\%), scapula $(20.0 \%)$, trochanter $(14.1 \%)$ and malleolus $(5.7 \%)$ regions (Table 3).

\section{Discussion}

The Braden Scale showed to have best in a number of widely used scales for assessing risk of PU in ICUs. The purpose of the scale is to help health professionals, especially nurses, assess a patient's risk of developing a PU (15) The risk of PU development as defined in this study, score according to the Braden Scale was less than or equal to 18 . The scores decreased with an increase in the risk of PU development. Preventive measures taken generally similar according to the scores obtained in the Braden Scale, only small differences may be observed between the groups of different risk levels (23).

The incidence of PUs in patients at risk for PU according to the Braden Score in ICUs in this study was found to be $17.0 \%$. PU incidence is not high compared with studies in other countries in which the incidence of PU in ICU patients has been reported to be between 3-33\% $(11,19,32)$.

All of the patients who were diagnosed with PUs were patients at 'high risk', 'very high risk' and risk according to the Braden score. This is also supported by our finding that none of the patients in the 'no risk' group developed a PU (Table 1).

Table 2. The relation between PU and baseline Braden Subscales scores of patient

\begin{tabular}{|c|c|c|c|c|}
\hline Braden Risk Assessment & n (\%) & $\begin{array}{c}\text { New Development PUs } \\
n\end{array}$ & $\begin{array}{c}\text { No Development New PUs } \\
n\end{array}$ & $\mathrm{p}$ \\
\hline \multicolumn{5}{|l|}{ Sensory perception } \\
\hline Completely limited & $76(23.5)$ & 18 & 58 & \multirow{4}{*}{$\mathrm{p}=0.04$} \\
\hline Very limited & $22(6.8)$ & 7 & 15 & \\
\hline Slightly limited & $59(18.2)$ & 10 & 49 & \\
\hline No impairment & $167(51.7)$ & 20 & 147 & \\
\hline \multicolumn{5}{|l|}{ Moisture } \\
\hline Completely moist & $2(0.6)$ & 0 & 2 & \multirow{4}{*}{$\mathrm{p}=0.20$} \\
\hline Very moist & $2(0.6)$ & 0 & 2 & \\
\hline Occasionally moist & $2(0.6)$ & 0 & 2 & \\
\hline Rarely moist & $270(83.5)$ & 52 & 218 & \\
\hline \multicolumn{5}{|l|}{ Activity } \\
\hline Bedfast & $298(92.2)$ & 55 & 243 & \multirow{2}{*}{$\mathrm{p}=0.20$} \\
\hline Walks occasionally & $24(7.4)$ & 0 & 24 & \\
\hline \multicolumn{5}{|l|}{ Mobility } \\
\hline Completely immobile & $22(6.8)$ & 20 & 2 & \multirow{4}{*}{$\mathrm{p}=0.60$} \\
\hline Very limited & $65(20.1)$ & 10 & 55 & \\
\hline Slightly limited & $83(25.6)$ & 17 & 66 & \\
\hline No limitation & $91(28.1)$ & 8 & 83 & \\
\hline \multicolumn{5}{|l|}{ Nutrition } \\
\hline Very poor & $45(13.9)$ & 12 & 33 & \multirow{4}{*}{$\mathrm{p}=0.20$} \\
\hline Probable inadequate & $91(28.1)$ & 16 & 75 & \\
\hline Adequate & $182(56.3)$ & 27 & 155 & \\
\hline Excellent & $5(1.5)$ & 0 & 5 & \\
\hline \multicolumn{5}{|l|}{ Friction and shear } \\
\hline Problem & $130(40.2)$ & 28 & 102 & \multirow[t]{3}{*}{$\mathrm{p}=0.03$} \\
\hline Potential problems & $111(34.3)$ & 21 & 90 & \\
\hline No apparent problems & $82(25.3)$ & 6 & 76 & \\
\hline Total & & 323 & & \\
\hline
\end{tabular}

East J Med Volume:21, Number:1, January-March/2016 
Table 3. Overview incidences by stage and location

\begin{tabular}{lcccc}
\hline Location & $\begin{array}{c}\text { I. stage } \\
\mathbf{n ~ ( \% )}\end{array}$ & $\begin{array}{c}\text { II. stage } \\
\mathbf{n}(\mathbf{\%})\end{array}$ & $\begin{array}{c}\text { III. stage } \\
\mathbf{n ( \% )}\end{array}$ & $\begin{array}{c}\text { Total } \\
\mathbf{n}(\mathbf{\%})\end{array}$ \\
\hline Sacrum & $16(15.2)$ & $9(9.5)$ & - & $25(49.5)$ \\
Scapula & $16(15.2)$ & $5(4.8)$ & - & $21(20.0)$ \\
Trokanter & $4(3.8)$ & $4(3.8)$ & $1(1.0)$ & $9(14.1)$ \\
Malleol & $6(5.7)$ & - & - & $6(5.7)$ \\
Others & $16(15.2)$ & - & - & $16(15.2)$ \\
\hline
\end{tabular}

Similarly, Sayar et al. (19) found the mean another a risk score instrument of patients developing a PU that according to the Braden score classification, indicates 'very high risk'. that the Braden score has been shown to have predictive ability for patients in an ICU. Of the six subscales, only sensory perception, and friction and rupture subscales were a significant predictor of PUs in this study. Mobility is defined on the Braden Scale as ability of patient to turn and control body movement. This study, compared with patients whom were no PU, patients in whom PU developed had significant lower scores on the mobility subscale, defined as very limited mobility (15). The result are consistent with others reported in the literature $(11,15,33)$.

PU development within the Surgical ICU was statistically higher than Medical ICU. In the Surgical ICU, one of the surgery-related risk factors is having an extended period of pressure during the surgical procedure, remaining wet, metabolic and circulatory changes related to the surgical procedure and anaesthesia (19).

There were 77 PUs developed in total of 57 patients. Stage I PUs were observed in 13\% patients, Stage II in $4.3 \%$ patients, and Stage III in $3.0 \%$ patient. That stage of the Pus were the same throughout the study. It was observed that the majority of new PUs were Stage I. In Sayar et al. (19) study conducted in Turkey, 23 of 140 patients had Stage I PUs, and 4 patients had Stage II PUs. In other study, the more severe PUs were reported to be in ICUs, of which $42 \%$ were Stage II and $28.5 \%$ - were stage I in ICU (25).

The distribution according to PU regions revealed that Stage I and Stage II PUs were mostly observed in sacrum and followed by scapula in this study. The reasons for this may be the fact that the majority of patients are kept in a semifowler's position, which puts more pressure on the sacrum and shoulder and because of an increase in friction and shearing from incorrect lifting techniques of the patients slipping downwards in the bed by healthcare givers (19).
Although PUs may be observed at any region of the body, $95 \%$ are observed in the sacrum parts. Although studies have shown differences between the rates of PU location, the most frequently observed locations are sacral, trochanteric, ischium, and malleolar regions (15,19,34,35). Otherwise the malleol and heel were found as sites of PUs in this study. This result has not been approved yet by other studies and could be noted in futher research (25).

In this study, showed no significant relationship beetween PU and age. It has been reported in literature that, due to impairment in the skin turgor and frequent chronic diseases, an increased risk of PU development in the elderly (65 years of age or older) was observed, which reached an Evidence C level $(26,28)$. The rate of PU development in the same age group is high according to the existing literature. The studies of Kurtuluş and Pınar (16), Sayar et al. (19), Bergstom et al. (28), Chan et al. (36) also revealed no significant difference between age groups and development of PUs.

Gender was not a PU risk factor in this study. However, other studies demonstrate higher rates of PU development in women than men (19). According to the EPAUP guidelines, age and gender parameters are factor in the development of PUs (31). In similar to studies, gender was not found to be a factor affecting PU development $(16,19,37)$.

The findings showed that a significant correlation was observed between PU development and the length of stay, confinement to bed, and poor consciousness. In similar studies, the duration of hospital stay among the patients with PUs was determined to be longer, and a positive and highly significant difference was found between PU development and the length of stay $(16,38)$. In this study, standing the patient on his or her feet during the day was considered active movement. The causes of PUs frequently observed in intensive care patients includ insufficient physical 
activity and movement, confinement to the bed for a long time, conventional use of various drugs such as anesthetics, sedatives, analgesics and muscle relaxers, and the use of mechanical ventilation. Due to unconsciousness and drug use, the patients cannot perceive the increased tissue pressure and cannot react so as to request the alleviation of the pressure (39).

Additionaly, there was significant difference between the BMI values, PUs were statistically significantly more common among the "obese" population. The existing literature reports that PU development is more common among patients with a BMI value not within the normal limits (40). In obese patients, PU development is increased though many causes including the reduced tolerance against friction due to poor circulation within the fat, difficulties in turning and positioning the patients, and an increase in moisture in the curves of the skin $(2,16,38,40)$. According to these results, obesity was defined as a risk increasing factor in this study.

No statiscally significant correlation was observed between PU development and hemoglobin $(\mathrm{Hg})$ levels, albumin levels and diabetes (Table 1). In has been reported in literature that an Evidence C level diabetes, anemia, and hypoalbuminemia are factors that increase the risk of PU development (31). In a large population studies reported anemia as a causative factor in the development of PUs (40). However, there are Kurtuluş \& Pinar (16) and Sayar et al. (19) studies indicating no correlation between anemia and PU development. In some studies, serum albumin level was defined as a risk factor $(37,41,42)$.

Two different types of viscoelastic foam mattresses were the preventive devices most frequently applied to patients in ICUs. No difference was observed between the viscoelastic mattresses regarding the development of PUs in ICUs. The use of specialized mattress to prevent PUs is common in the ICU, although indications are largely anecdotal. Some studies suggest that they are beneficial but only to populations outside the ICU environment. Findings are often extrapolated to critically ill patients (25). The use of specialized foam mattreses and regular turning and repositioning of immobile patients may be two important care for preventing PU (15). The most important factor in reducing the pressure on the tissue is the interval of turning the patient $(15,32)$. During the study, the routine prevention measures taken in ICU for reducing PUs is repositioning and turning the patient. This standard procedure should be performed once every two hours, however, the repositioning may be performed at impaired intervals due to the working hours of nurses in ICU (32). Furthermore, patients skin should be wiped a minimum of two times daily, and preventive applications should be performed for fecal or urinary incontinences (7). Therefore, in this study, patient skin care was performed two times daily by nurses, their skin was moisturized with vaseline, and the patients were repositioned once every two hours. Independent from the investigators, nurses reported their observations regarding patients skin during their care.

Braden subscales, sensory perception, and friction and rupture subscales were identified as being predictive of PUs development in this study. Furthermore, a statiscally significant correlation was observed between the duration of PU development and higher risk score, elderly, unconscious and immobilized and length of stay in bed. In addition to this study result, none of the patients in the 'no risk' group developed PUs. According to this results of study, Braden Scale is recommended to reduce development $\mathrm{PU}$ and define better prediction of PU for giving more effective nursing care patient with risk factor in ICU.

\section{References}

1. Strachan V. PUPPS 3 pressure ulcer point prevalence survey: statewide report 2006. Melbourne: Victorian Government Department of Human Services, 2006, pp 1 - 4.

2. European Pressure Ulcer Advisory Panel, National Pressure Ulcer Advisory Panel (EPUAP and NPUAP). Prevention and treatment of pressure ulcers: quick reference guide. Washington DC: National Pressure Ulcer Advisory Panel, 2009: pp 7-42.

3. Reddy M, Gill SS, Rochon P. Preventing pressure ulcers: a systematic review. JAMA 2006; 96: 974-984.

4. Keller B, Lubbert W, Keller E, Leenen H. Tissue-interface pressure on three different support surfaces for trauma patients, Injury. Int. J. Care Injured 2005; 36: 946-948.

5. Tokgöz OS, Demir O. Pressure ulcers incidence and risk factors in ICU of norology: Selcuk medical research manuscript. Selcuk Tip dergisi 2010; 26: 95-98 (in Turkish).

6. Athlin E, Idvall E, Jernfa M. Factors of importance to the development of pressure ulcers in the care trajectory: perceptions of hospital and community care nurses. Journal of Clinical Nursing 2009; 3: 2-23.

7. Theaker C. Pressure sore prevention in the critically ill: what you don't know, what you

East J Med Volume:21, Number:1, January-March/2016 
should know and why it's importance, current. Anaesthesia \& Critical Care 2002; 13: 201-205.

8. Akyol A. Intervention studies for prevention of pressure ulcer in Turkey: a literature review. International Nursing Review 2006; 53: 308-316.

9. McKinley S, Elliott R, Fox V. Quality improvement program to reduce the prevalence of pressure ulcers in an intensive care unit, American Journal of Critical Care 2008; 17: 235237.

10. Nijs N, Toppets A, Defloor T, et al. Incidence and risk factors for pressure ulcers in the intensive care unit. Journal of Clinical Nursing 2008; 18: 1258-1266.

11. Bours G, De Laat E, Halfens R, Lubbers M. Prevalence, risk factors and prevention of pressure ulcers in Dutch intensive care units. Intensive Care Med 2001; 27: 1599-1605.

12. Sewchuk D, Padula C, Osborne E. Prevention and early detection of pressure ulcers in patients undergoing cardiac surgery. AORN Journal 2006; 84: 75-77.

13. Vanderwee K, Grypdonck MH, DeBacquer D, Defloor T. Effectiveness of turning with unequal time intervals on the incidence of pressure ulcer lesions. J Adv Nurs 2007; 57: 5968.

14. Haleem S, Heinert G, ParkerS MJ. Pressure sores and hip fractures, injury. Int $\mathrm{J}$ Care Injured 2008; 39: 219-223.

15. Cox J. Predictive power of the Braden scale for pressure sore risk in adult critical care patients. J Wound Ostomy Continence Nurs 2012; 39: 1-9.

16. Kurtuluş Z, Pınar R. Relation between albumin levels and pressure sore in high-risk patients defined with Braden's Risk Assessment tool. C.U Hemşirelik Y.O Dergisi 2003; 7: 1-10 (in Turkish).

17. Karadağ M, Gümüşkaya N. The incidence of pressure ulcers in surgical patients: a sample hospital in Turkey. Journal of Clinical Nursing 2005; 15: 413-421.

18. Uzun O, Tan M. A prospective, descriptive pressure ulcer risk factor and prevalence study at a university hospital in Turkey. Ostomy/Wound Management 2007; 53: 44-56.

19. Sayar S, Turgut S, Doğan H, et al. Incidence of pressure ulcers in intensive care unit patients at risk according to the Waterlow Scale and factors influencing the development of pressure ulcers. Journal Of Clinical Nursing 2009; 18: 765-774.

20. İnan DG, Özatunç G. Pressure ulcer prevalence in Turkey: a sample from a university hospital. J Wound Ostomy Continence Nurs 2012; 39: 409413.

21. Kottner J, Dassen T. Pressure ulcer risk assessment in critical care: interrater reliability and validity studies of the Braden and Waterlow scales and subjective ratings in two intensive care units. International Journal of Nursing Studies 2010; 47: 671-677.
22. Hyun S, Vermillion B, Newton C. Predictive validity of the Braden Scale for patients in intensive care units. American Journal Critical Care 2013; 22: 514-520.

23. Cakmak SK, Gül U, Ozer S, Yiğit Z, Gönü M. Risk factors for pressure ulcers. Adv Skin Wound Care 2009; 22: 412-415.

24. Tel H, Özden D, Çetin PG. Determination of risk for pressure ulcer development in bedridden patients and preventive measures that nurses use for these patients. Hemşirelikte Araştırma ve Geliştirme Dergisi 2006; 1: 35-46 (in Turkish).

25. Shahin E, Dassen T, Halfens R. Incidence, prevention and treatment of pressure ulcers in intensive care patients: a longutidunal study. International Journal of Nursing Studies 2009; 46: 413-421.

26. Rycroft MJ, Rycroft MJ. Recommendation risk factors. In Rycroft M (eds). Pressure Ulcer Risk Assessment And Prevention Clinical Practice Guidelines. London, 2001, pp 12-18.

27. Teasdale G, Jennett B. Assessment of coma and impaired consciousness: a practical scale. Lancet 1974; 2: 81-84.

28. Bergstrom N, Braden B, Kemp M, Champagne M, Ruby E. Multi-site study of incidence of pressure ulcers and the relationship between risk level, demographic characteristics, diagnoses, and prescription of preventive interventions. J Am Geriatr Soc 1996; 44: 22-30.

29. Horn SD, Bender AS, Ferguson ML, et al. The national pressure ulcer long-term care study: pressure ulcer development in long-term care residents. Journal of the American Geriatrics Society 2004; 52: 359-367.

30. Unosson M, Krantz AN. A risk assesment scale for prediction of pressure sore development: reability and validity. Journal of Advanced Nursing 2002; 38: 190-199.

31. European Pressure Ulcer Advisory Panel and National Pressure Ulcer Advisory Panel (EPUAP and NPUAP). Pressure ulcers: defnitions and stages. Washington, DC: NPUAP; 2009, pp 7-12.

32. Theaker C, Kuper M, Soni N. Pressure ulcer prevention in intensive care: a randomised control trial of two pressure relieving devices. Anaesthesia 2005; 60: 395-400.

33. Jiricka M, Ryan P, Carvalho M, Bukvich J. Pressure ulcer risk factors in an ICU population. American Journal Critical Care 1995; 4: 361-367.

34. Nixon J, Cranny G, Iglesias C. Randomised, controlled trial of alternating pressure matresses compared with alternating pressure overlays for the prevention of pressure ulcers: pressure (pressure relieving support surface) trial. BMJ 2006; 332: 1-5.

35. Toshiko K, Tokunaga K, Matsui N, Sanada H. Risk factors related to the development of 
pressure ulcers in the critical care setting. Journal of Clinical Nursing 2010; 19: 414-421.

36. Chan WS, Samantha MCP, Know EWY. Assessing predictive validity of the modified Braden scale for prediction of pressure ulcer risk of orthopaedic patients in an acute care setting. Journal of Clinical Nursing 2009; 18: 1565-1573.

37. Anthony D, Reynolds T, Russell L. An investigation into the use of serum albumin in pressure sore prediction. Journal Advenced Nursing 2000; 32: 59-65.

38. Mollaoğlu M, Tuncay FO, Fertekli TK. Investigation with Braden Scale of pressure wound risk in the patients with cerebrovascular disease. I.Ü.Florence Nightingale Hemşirelik Y.O Dergisi 2008; 16: 150-156 (in Turkish).

39. Girgin NK, Erar1 GK. Pressure ulcer care. Klimik Dergisi 2007; 20: 5-6 (in Turkish).

40. Sharp CA. Pressure ulcers. Thesis edition (M.P.H) University of New South Wales, 2006.

41. Berlowitz DR, Wilking SVB. Risk factors for pressure sores: a comparison of cross- sectional and cohort-derived data. Journal American Geriatrics Society 1989; 37: 1043-1050.

42. Reed RL, Hepburn K, Adelson R. Low serum albumin levels, confusion and fecal incontinence: are these risk factors for pressure ulcers in mobility-impaired hospitalized adults? Gerontology 2003; 49: 255-259. 